Arq. Bras. Med. Vet. Zootec., v.61, supl. 1, p.126-134, 2009

\title{
Situação epidemiológica da brucelose bovina no Estado do Tocantins
}

[Epidemiological situation of bovine brucellosis in the State of Tocantins, Brazil]

\author{
R.A. ggata $^{1}$, V.S.P. Gonçalves ${ }^{2}$, V.C.F. Figueiredo ${ }^{3}$, J.R. Lobo $^{3}$, A.L. Rodrigues ${ }^{4}$, M. Amaku ${ }^{1}$, \\ F. Ferreira ${ }^{1}$, J.S. Ferreira Neto ${ }^{1}$, R.A. Dias ${ }^{1 *}$ \\ ${ }^{1}$ Faculdade de Medicina Veterinária e Zootecnia - USP \\ Av. Prof. Dr. Orlando Marques Paiva, 87 \\ 05508-270 - São Paulo, SP \\ ${ }^{2}$ Faculdade de Agronomia e Medicina Veterinária - UnB - Brasília, DF \\ ${ }^{3}$ Departamento de Saúde Animal - SDA-MAPA - Brasília, DF \\ ${ }^{4}$ Agência de Defesa Agropecuária do Estado do Tocantins - SEAGRO - Palmas, TO
}

\begin{abstract}
RESUMO
Realizou-se um estudo para caracterizar a situação epidemiológica da brucelose bovina no Estado do Tocantins, entre fevereiro de 2002 e agosto de 2003. O Estado foi dividido em seis áreas com características produtivas homogêneas (circuitos produtores). Para cada área, foi calculada uma amostragem simples aleatória de 300 propriedades, com o objetivo de estimar a prevalência de focos de brucelose além da prevalência de fêmeas bovinas adultas soropositivas. Para isso, foram amostradas de 10 a 15 vacas com idade superior a dois anos em cada propriedade. Um total de 20.908 soros foi obtido de 1.842 propriedades. A prevalência de focos de brucelose foi de 21,2\% [19,3-23,1\%] e a prevalência de fêmeas bovinas adultas soropositivas de 4,4\% [3,6-5,3\%] para o Estado. Quando se considerou o circuito produtor, observou-se que os circuitos $1,2,3$ e 5 tiveram prevalência de focos significativamente maior que os circuitos 4 e 6 . Os resultados da prevalência nos circuitos $1,2,3$ e 5 foram de: $16,0 \%$ [12,1$20,6 \%], 37,6 \%$ [32,1-43,4\%], 26,4\% [21,5-31,7\%] e 29,3\% [24,3-34,7\%], respectivamente. Nos circuitos 4 e 6 , foram de 5,8\% [3,5-9,1\%] e 8,6\% [5,7-12,2\%], respectivamente. Em cada propriedade, foi aplicado um questionário epidemiológico, com o objetivo de avaliar o grau de associação de possíveis fatores de risco com a doença. Os fatores de risco (odds ratio, OR) associados à condição de foco de brucelose foram: rebanho com mais de 120 vacas $(\mathrm{OR}=2,0)$ e abate de reprodutores na propriedade $(\mathrm{OR}=$ $1,52)$. Vacinação contra brucelose $(\mathrm{OR}=0,37)$, presença de piquete de parição $(\mathrm{OR}=0,72)$ e exploração de leite $(\mathrm{OR}=0,63)$ apresentaram-se como fatores de proteção.
\end{abstract}

Palavras-chave: bovino, brucelose, prevalência, fatores de risco, Tocantins

\begin{abstract}
A study was carried out to characterize the epidemiological situation of brucellosis in the State of Tocantins from February 2002 to August 2003. The State was divided into six regions with a homogeneous productive system. For each region, a simple random sample was calculated to estimate the prevalence both in farms and cows older than two-year. To achieve this, from 10 to 15 adult cows (older than two-year) were sampled. A total of 20,908 sera from 1,842 farms were obtained. For the whole State of Tocantins, the prevalence of positive farms (or farms with at least one positive animal) was 21.2\% [19.3-23.1\%]. When the production regions were considered, the prevalences for the regions 1, 2, 3, and 5 were: $16.0 \%$ [12.1-20.6\%], 37.6\% [32.1-43.4\%], 26.4\% [21.5-31.7\%], and 29.3\% [24.3$34.7 \%]$, respectively. In the regions 4 and 6 , the prevalences were $5.8 \%$ [3.5-9.1\%] and 8.6\% [5.7$12.2 \%]$, respectively. In each visited farm, a questionnaire was applied, in order to evaluate the association between with possible risk factors and the brucellosis. The risk factors (odds ratio, OR) associated with the infected herds were number of cows above 120 (OR=2.0) and slaughtering of
\end{abstract}

Recebido em 27 de março de 2009

Aceito em 23 de setembro de 2009

* Autor para correspondência (corresponding author)

E-mail: dias@vps.fmvz.usp.br 
breeding animals in the farm $(O R=1.52)$. Vaccinating against brucellosis $(O R=0.37)$, presence of birth pen $(O R=0.72)$, and dairy farm $(O R=0.63)$ presented as protective factors.

Keywords: cattle, brucellosis, prevalence, risk factors, Tocantins, Brazil

\section{INTRODUÇÃO}

O Estado do Tocantins, criado em 1988, a partir da divisão do Estado de Goiás, está localizado no centro geodésico do Brasil. Ocupa uma área de $277.620,914 \mathrm{~km}^{2}$ e tem uma população humana de 1.305 .728 habitantes (IBGE, 2005). Caracteriza-se por ter na agricultura o setor que absorve a maior parte da população economicamente ativa. A agropecuária contribui com $60 \%$ do PIB, e é a principal atividade econômica do Estado, com destaque para a criação de gado de corte, seguida pela produção de soja e arroz. Atividades como suinocultura e avicultura são incipientes no Estado. Com uma economia em fase de crescimento, a movimentação do comércio atrai indústrias, contribuindo para o desenvolvimento do Estado (Silva e Almeida, 2007).

$\mathrm{O}$ forte setor agropecuário deve-se à bovinocultura bastante ativa e em desenvolvimento, justamente pela migração da pecuária para as regiões Centro-Oeste e Norte do País. Nos últimos 20 anos, Tocantins apresentou uma das maiores taxas de crescimento da população bovina do País, registrando aumento de $63 \%$ do seu plantel. Conforme estimativa realizada em 2005, o rebanho bovino tocantinense era de 7.961.926 cabeças, sendo o terceiro maior rebanho da região Norte do País. O rebanho bubalino é bem menor, com 9.260 animais, considerado o quarto maior rebanho do norte brasileiro (IBGE, 2005).

Em 2004, estavam registrados 6,7 milhões de hectares de pastagens e, atualmente, é o $11^{\circ}$ maior Estado brasileiro produtor de gado bovino. Pode-se destacar a presença das raças Gir, para corte e leite, e Nelore, para corte, que representam, aproximadamente, $86 \%$ do rebanho do Estado. A preferência pelas raças zebuínas é atribuída à adaptabilidade delas ao clima quente e úmido, característico da região (IBGE, 2005).

A pecuária é uma das mais representativas atividades produtivas do Estado. Devido aos incentivos oferecidos pela Secretaria da Fazenda (SEFAZ), o potencial para aumentar a produção pecuária é grande, favorecendo o estabelecimento de novas empresas, voltadas para essa atividade e, consequentemente, absorvendo a mão-de-obra existente. $\mathrm{O}$ governo estadual reduziu o ICMS sobre a carne (3\%), para estimular a produção de carne com qualidade (sanidade), ou seja, diminuindo a produção clandestina. Aliado a isto, foi criado o Sindicato das Indústrias de Curtumes do Tocantins que proporcionou, ao Estado, vantagens competitivas no comércio de couro. A pecuária leiteira também vem crescendo nos últimos anos, com o programa de geração de empregos e renda com fomento à bacia leiteira, propiciando a instalação de 25 miniusinas. Além disso, o programa do Estado visa subsidiar a compra de matrizes leiteiras, a aquisição de sêmen e de implementos agrícolas, a construção de prédios e a aquisição de outros equipamentos (Tocantins, [200-]b).

Tocantins apresenta crescimento expressivo do seu plantel bovino devido à demanda do mercado, principalmente de carne, do próprio Estado e de alguns estados do Nordeste.

A Regional de Araguatins faz parte da microrregião denominada de Bico do Papagaio. Possui um rebanho bovino pequeno, de 722.053 cabeças, distribuído em 7.969 propriedades com atividades reprodutivas. Por se tratar de uma região que não integra o eixo de desenvolvimento, denominado de "corredor modal", não há muita diversificação produtiva, nem a existência de indústrias ou agroindústrias importantes. Por esse motivo, é considerada a região mais pobre de Tocantins. A principal atividade econômica é a pecuária de corte extensiva. Nessa regional, há também um grande laticínio, pertencente a uma cooperativa, em Augustinópolis. Devido a esse fato, na região predominam animais mestiços, com aptidão para produzir carne e leite (Tocantins, [200-]a).

Nas regionais de Pedro Afonso, Palmas e Porto Nacional, a pecuária também é pouco expressiva. $\mathrm{O}$ rebanho bovino é pequeno quando comparado com o rebanho de outros circuitos produtores. Nessas regionais há aproximadamente 771.538 cabeças, onde predominam animais mestiços. 
Neste circuito concentra-se a maior produção de grãos do Estado, principalmente soja. A soja é considerada o principal produto de exportação tocantinense, representando $88,8 \%$ das exportações de grãos, a maior parte com destino à Europa.

No restante do Estado predomina um perfil bastante homogêneo. De forma geral, a pecuária de corte é a principal atividade econômica, e $42,8 \%$ das propriedades adotam a exploração extensiva $(67,0 \%$ da criação). As raças predominantes nessas regiões são as zebuínas destinadas à produção de carne.

O Ministério da Agricultura, Pecuária e Abastecimento publica, anualmente, dados oficiais brasileiros sobre as principais doenças, por meio de Boletins de Defesa Sanitária Animal. Em publicações anteriores à década de 90 não constavam dados da brucelose bovina na região Norte do País, com exceção do Estado do Pará, que notificou alguns casos em 1975. Os primeiros registros oficiais da doença nesta região ocorreram a partir de 1993, quando foram encontrados $12(3,1 \%)$ animais sororreagentes, no Amapá. Em 1995, foram notificados 195 $(7,9 \%)$ animais sororreagentes no Acre e 91 (5,7\%) no Amazonas e, em 1997, houve a notificação de $8531 \quad(13,0 \%)$ animais sororreagentes em Rondônia, 68 (1,6\%) em Roraima, 265 (3,3\%) em Tocantins e 904 (5,9\%) em Goiás. Apesar de os dados não serem provenientes de estudos planejados, pode-se afirmar que a doença está presente em todo o território nacional, uma vez que todos os demais Estados brasileiros já notificaram a existência de animais sororreagentes (Paulin e Ferreira Neto, 2002).

O Estado do Tocantins nunca teve um programa próprio de combate à brucelose bovina e a real situação epidemiológica da doença não é adequadamente conhecida. Portanto, o presente estudo teve por objetivos estimar a prevalência e identificar os fatores de risco para a brucelose bovina no Estado, e fornecer subsídios para a melhor implantação e gestão do Programa Nacional de Controle e Erradicação de Brucelose e Tuberculose.

\section{MATERIAL E MÉTODOS}

O estudo foi planejado por técnicos do Ministério da Agricultura, Pecuária e
Abastecimento, da Universidade de São Paulo e da Universidade de Brasília, em colaboração com os técnicos da Agência de Defesa Agropecuária do Estado do Tocantins (ADAPEC). O trabalho de campo foi realizado por técnicos da ADAPEC, no período de fevereiro de 2002 a agosto de 2003, após terem sido treinados para padronização de procedimentos.

Para o conhecimento das diferenças regionais nos parâmetros epidemiológicos da brucelose bovina, o Estado do Tocantins foi dividido em seis circuitos produtores de bovinos, levando em consideração os diferentes sistemas de produção, práticas de manejo, finalidades de exploração, tamanho médio de rebanhos e sistemas de comercialização. A divisão do Estado em regiões correspondentes a circuitos produtores também levou em conta a capacidade operacional e logística do serviço veterinário oficial do Estado para a realização das atividades de campo, baseando-se nas áreas de atuação das suas unidades regionais.

Em cada circuito produtor, estimou-se a prevalência de propriedades infectadas pela brucelose bovina e a de animais soropositivos por meio de um estudo amostral em dois estágios, dirigido para detectar focos da doença. No primeiro estágio, sorteou-se, aleatoriamente, um número pré-estabelecido de propriedades com atividade reprodutiva (unidades primárias de amostragem). No segundo, sorteou-se um número pré-estabelecido de fêmeas bovinas com idade igual ou superior a 24 meses (unidades secundárias de amostragem).

Nas propriedades rurais onde existia mais de um rebanho, foi escolhido o rebanho bovino de maior importância econômica, no qual os animais estavam submetidos ao mesmo manejo, ou seja, sob os mesmos fatores de risco. A escolha da unidade primária de amostragem foi aleatória, baseada no cadastro de propriedades rurais com atividade reprodutiva de bovinos. A propriedade sorteada que, por motivos vários, não pôde ser visitada, foi substituída por outra, nas proximidades e com as mesmas características de produção. $\mathrm{O}$ número de propriedades selecionadas por circuito foi estimado pela fórmula para amostras simples aleatórias (Thrusfield, 2007). Os parâmetros adotados para o cálculo foram: nível de 
confiança de 0,95 , prevalência estimada de 0,25 e erro de 0,05. A capacidade operacional e financeira do serviço veterinário oficial do Estado também foi levada em consideração para a determinação do tamanho da amostra por circuito.

O planejamento amostral para as unidades secundárias visou estimar um número mínimo de animais a serem examinados dentro de cada propriedade de forma a permitir a sua classificação como foco ou não foco de brucelose. Para tanto, foi utilizado o conceito de sensibilidade e especificidade agregadas (Dohoo et al., 2003). Para efeito dos cálculos foram adotados os valores de $95 \%$ e $99,5 \%$, respectivamente, para a sensibilidade e a especificidade do protocolo de testes utilizado (Fletcher et al., 1998) e 20\% para a prevalência estimada. Nesse processo foi utilizado o programa Herdacc versão 3, e o tamanho da amostra escolhido foi aquele que permitiu valores de sensibilidade e especificidade de rebanho iguais ou superiores a 90\%. Assim, nas propriedades com até 99 fêmeas com idade superior a 24 meses, foram amostrados 10 animais e nas com 100 ou mais fêmeas com idade superior a 24 meses, 15 animais. A escolha das fêmeas dentro das propriedades foi casual sistemática.

O protocolo do sorodiagnóstico foi composto pela triagem com o teste do antígeno acidificado tamponado (Rosa Bengala), seguida do reteste dos positivos com o teste do 2-mercaptoetanol, de acordo com as recomendações do PNCEBT (Brasil, 2006). O sangue foi coletado por punção da veia jugular com agulha descartável estéril em tubo com vácuo, previamente identificado. Os soros, armazenados em microtubos de plástico, foram mantidos a $-20^{\circ} \mathrm{C}$ até a realização dos testes. Os testes sorológicos foram realizados no Laboratório Central de Saúde Pública (LACEN, SES-TO).

A propriedade foi considerada positiva quando se detectou pelo menos um animal positivo. As propriedades que apresentaram animais com resultado sorológico inconclusivo, sem nenhum positivo, foram classificadas como suspeitas e excluídas das análises. $\mathrm{O}$ mesmo tratamento foi dado aos animais com resultados sorológicos inconclusivos.

O planejamento amostral permitiu determinar as prevalências de focos e de fêmeas adultas $(\geq 24 \mathrm{~m})$ soropositivas para brucelose no Estado e também nos circuitos produtores. Os cálculos das prevalências aparentes e os respectivos intervalos de confiança foram realizados conforme preconizado por Dean et al. (1994). Os cálculos das prevalências de focos e de animais no Estado, e de prevalências de animais dentro das regiões foram feitos de forma ponderada (Dohoo et al., 2003).

O peso de cada propriedade no cálculo da prevalência de focos no Estado foi dado por

$$
P_{1}=\frac{\text { propriedades na região }}{\text { propriedades amostradas na região }}
$$

O peso de cada animal no cálculo da prevalência de animais no Estado foi dado por

$$
P_{2}=\frac{\text { fêmeas } \geq 24 \text { meses na propriedade }}{\text { fêmeas } \geq 24 \text { meses amostradas na propriedade }} \times \frac{\text { fêmeas } \geq 24 \text { meses na região }}{\text { fêmeas } \geq 24 \text { meses nas propriedades amostradas na região }}
$$

$\mathrm{Na}$ expressão acima, o primeiro termo refere-se ao peso de cada animal no cálculo das prevalências de animais dentro das regiões.

Em cada propriedade amostrada, além da coleta de sangue para a sorologia, foi também aplicado um questionário epidemiológico, elaborado para obter informações sobre o tipo de exploração e as práticas de manejo empregadas. Nesse estudo tipo transversal, as variáveis analisadas foram: tipo ou sistema de exploração (carne, leite e misto), tipo de criação (confinado, semiconfinado, extensivo), uso de inseminação artificial, raças predominantes, número de vacas com idade superior a 24 meses, número de bovinos na propriedade, presença de outras espécies domésticas, presença de animais silvestres, destino da placenta e dos fetos abortados, compra e venda de animais, vacinação contra brucelose, abate de animais na 
propriedade, aluguel de pastos, pastos comuns com outras propriedades, pastos alagados, piquete de parição e assistência veterinária.

As variáveis foram organizadas de modo a apresentarem-se em escala crescente de risco. Quando necessário, realizou-se a recategorização dessas variáveis. A categoria de menor risco foi considerada como base para a comparação das demais categorias. As variáveis quantitativas foram categorizadas em percentis.

Foi feita uma primeira análise exploratória dos dados (univariada) para seleção daquelas com $\mathrm{p} \leq 0,20$ para o teste do $\chi^{2}$ ou exato de Fisher e, subsequente, oferecimento dessas à regressão logística. Os cálculos foram realizados com o auxílio do programa SPSS, versão 9.0.

Todas as informações geradas pelo trabalho de campo e de laboratório foram inseridas em um banco de dados específico, utilizado nas análises epidemiológicas.

\section{RESULTADOS E DISCUSSÃO}

O Estado do Tocantins foi dividido em seis circuitos produtores (Fig. 1). Na Tab. 1 são apresentados os dados censitários do Estado. As prevalências de focos e de fêmeas soropositivas para brucelose são apresentadas nas Tab. 2 e 3 . As prevalências de focos por tipo de exploração da propriedade encontram-se na Tab. 4.

Quanto ao número de fêmeas em idade reprodutiva no Estado, a mediana por propriedade foi de 50 (primeiro quartil = 21,5 e terceiro quartil $=120$ ). Ao fazer a estratificação por tipo de exploração, os valores encontrados foram: exploração do tipo corte $=56$ (primeiro quartil $=22$ e terceiro quartil = 142,5); exploração do tipo leite $=39$ (primeiro quartil = 20 e terceiro quartil $=66$ ); exploração do tipo misto $=48,5$ (primeiro quartil $=22$ e terceiro quartil $=98,5)$.

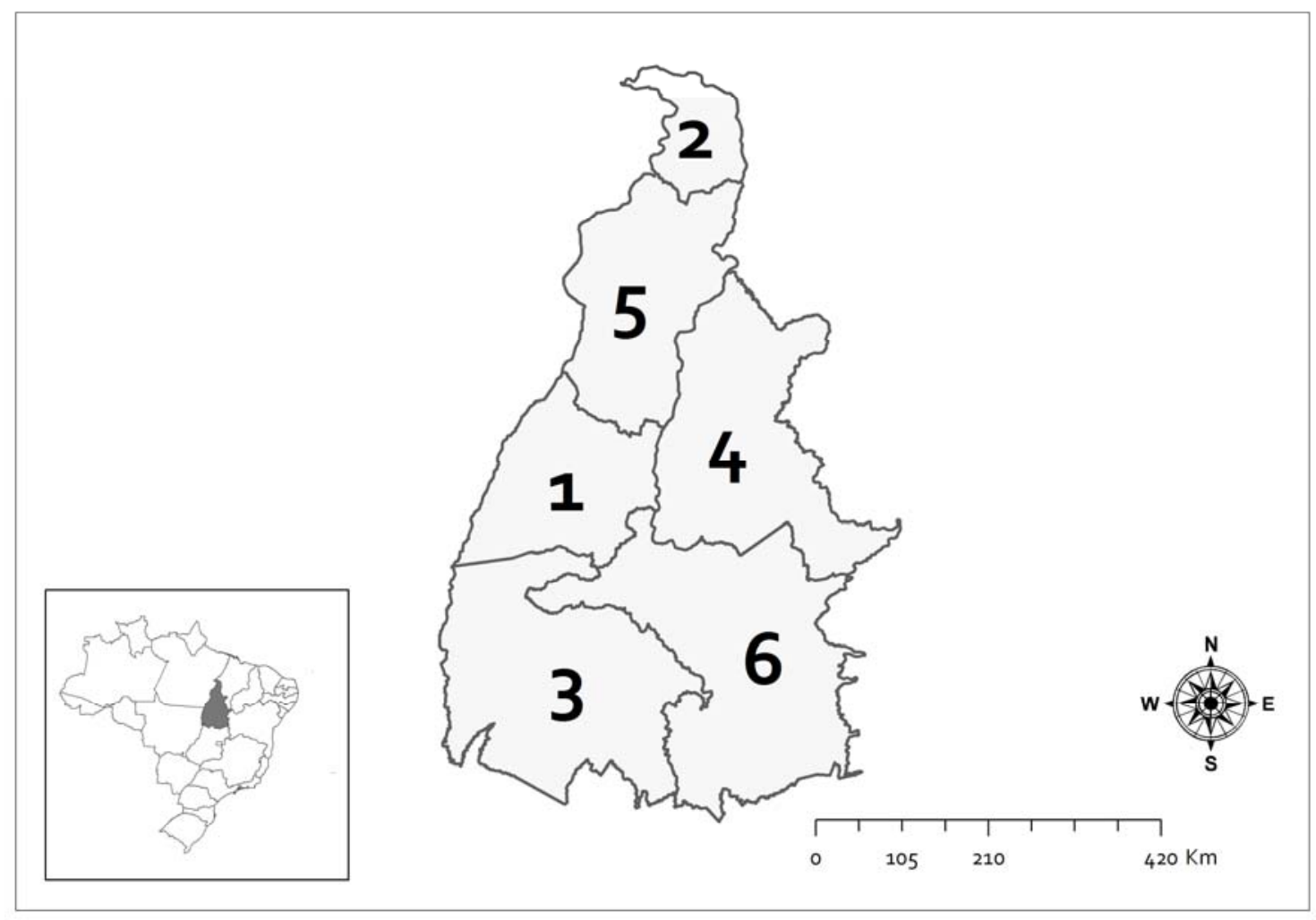

Figura 1. Mapa do Estado do Tocantins com a divisão em circuitos produtores. No detalhe, a localização do Estado do Tocantins no Brasil. 
Situação epidemiológica da brucelose bovina no Estado do Tocantins

Tabela 1. Dados censitários da população bovina do Estado do Tocantins em 2002, segundo o circuito produtor

\begin{tabular}{lcccc}
\multicolumn{1}{c}{ Circuito produtor } & $\begin{array}{c}\text { Propriedades } \\
\text { com atividade } \\
\text { reprodutiva }\end{array}$ & $\begin{array}{c}\text { Propriedades } \\
\text { Amostradas }\end{array}$ & $\begin{array}{c}\text { Fêmeas } \\
\text { 224 meses }\end{array}$ & $\begin{array}{c}\text { Fêmeas } \\
\text { amostradas }\end{array}$ \\
\hline 1- Paraíso do Tocantins & 6.837 & 306 & 505.357 & 3.382 \\
2- Araguatins & 7.696 & 295 & 239.997 & 3.022 \\
3- Gurupi e Formoso Araguaia & 9.706 & 307 & 751.619 & 3.902 \\
4- Palmas e Pedro Afonso & 6.771 & 308 & 190.203 & 3.167 \\
5- Colinas & 13.856 & 311 & 803.594 & 3.773 \\
6- Taguatinga & 11.739 & 315 & 573.418 & 3.662 \\
Total & 56.605 & 1.842 & 3.064 .188 & 20.908 \\
\hline
\end{tabular}

Tabela 2. Prevalência de focos de brucelose na propriedade, segundo o circuito produtor, no Estado do Tocantins

\begin{tabular}{lccccc}
\hline \multirow{2}{*}{ Circuito produtor } & \multicolumn{2}{c}{ Propriedades } & Prevalência & IC (95\%) \\
\cline { 2 - 3 } & Testadas & Positivas & & $(\%)$ & \\
\hline 1- Paraíso do Tocantins & 306 & 49 & & 16,01 & {$[12,08-20,61]$} \\
2- Araguatins & 295 & 111 & 37,63 & {$[32,08-43,43]$} \\
3- Gurupi e Formoso Araguaia & 307 & 81 & & 26,38 & {$[21,54-31,69]$} \\
4- Palmas e Pedro Afonso & 308 & 18 & & 5,84 & {$[3,50-9,08]$} \\
5- Colinas & 311 & 91 & & 29,26 & {$[24,26-34,66]$} \\
6- Taguatinga & 315 & 27 & & 8,57 & {$[5,72-12,23]$} \\
Total & 1.842 & 377 & & 21,22 & {$[19,33-23,11]$} \\
\hline
\end{tabular}

IC: intervalo de confiança.

Tabela 3. Prevalência de fêmeas sororreagentes para brucelose, segundo o circuito produtor, no Estado do Tocantins

\begin{tabular}{lccccc}
\hline \multirow{2}{*}{ Circuito produtor } & \multicolumn{2}{c}{ Animais } & \multirow{2}{*}{$\begin{array}{c}\text { Prevalência } \\
(\%)\end{array}$} & IC (95\%) \\
\cline { 2 - 3 } & Testados & Positivos & & 3,53 & {$[1,97-5,09]$} \\
\hline 1- Paraíso do Tocantins & 3.382 & 82 & & 8,54 & {$[5,89-11,18]$} \\
2- Araguatins & 3.022 & 223 & & 4,12 & {$[2,82-5,42]$} \\
3- Gurupi e Formoso Araguaia & 3.902 & 125 & & 2,00 & {$[0,00-4,04]$} \\
4- Palmas e Pedro Afonso & 3.167 & 26 & & 6,40 & {$[3,92-8,89]$} \\
5- Colinas & 3.773 & 183 & & 2,56 & {$[1,20-3,93]$} \\
6- Taguatinga & 3.662 & 49 & & 4,43 & {$[3,57-5,29]$} \\
Total & 20.908 & 688 & &
\end{tabular}

IC: intervalo de confiança. 
Tabela 4. Prevalência (Prev) de focos de brucelose bovina, estratificada por tipo de exploração, segundo o circuito produtor, no Estado do Tocantins

\begin{tabular}{|c|c|c|c|c|c|c|}
\hline \multirow[t]{2}{*}{ Circuito produtor } & \multicolumn{2}{|c|}{ Corte } & \multicolumn{2}{|c|}{ Leite } & \multicolumn{2}{|c|}{ Misto } \\
\hline & Prev (\%) & IC $(95 \%)$ & Prev (\%) & IC $(95 \%)$ & $\operatorname{Prev}(\%)$ & IC $(95 \%)$ \\
\hline 1- Paraíso do Tocantins & 16,24 & {$[11,75-21,60]$} & 16,67 & {$[3,58-41,42]$} & 15,09 & {$[6,75-27,59]$} \\
\hline 2- Araguatins & 37,21 & {$[22,86-46,15]$} & 36,84 & {$[26,06-48,69]$} & 39,33 & {$[29,13-50,25]$} \\
\hline $\begin{array}{c}\text { 3- Gurupi e Formoso } \\
\text { Araguaia }\end{array}$ & 27,87 & {$[22,34-33,95]$} & 10,00 & {$[1,23-31,71]$} & 25,58 & {$[13,52-41,17]$} \\
\hline 4- Palmas e Pedro Afonso & 6,28 & {$[3,47-10,31]$} & 8,33 & {$[0,21-38,48]$} & 4,11 & {$[0,86-11,54]$} \\
\hline 5- Colinas & 24,77 & {$[17,00-33,96]$} & 35,80 & {$[25,45-47,23]$} & 28,93 & {$[21,04-37,07]$} \\
\hline 6- Taguatinga & 9,04 & {$[5,45-13,92]$} & 5,26 & {$[0,64-17,25]$} & 8,97 & {$[3,68-17,62]$} \\
\hline
\end{tabular}

IC: intervalo de confiança.

Tabela 5. Resultados da análise univariada dos possíveis fatores de risco para brucelose bovina em rebanhos com atividade reprodutiva no Estado do Tocantins, 2003

\begin{tabular}{|c|c|c|c|}
\hline Variável & Expostos/Casos & $\begin{array}{l}\text { Expostos/ } \\
\text { Controles }\end{array}$ & $\mathrm{p}$ \\
\hline Tipo de exploração & - & - & 0,018 \\
\hline Exploração de corte $^{1}$ & $213 / 376$ & $925 / 1.462$ & 0,018 \\
\hline Exploração de leite ${ }^{2}$ & $65 / 376$ & $180 / 1.462$ & 0,011 \\
\hline Exploração mista $^{3}$ & $98 / 376$ & $357 / 1.462$ & 0,510 \\
\hline Tipo de criação & - & - & 0,557 \\
\hline Criação confinada ou semiconfinada ${ }^{4}$ & $19 / 377$ & $71 / 1.462$ & 0,875 \\
\hline Não usa IA ou usa IA e touro ${ }^{5}$ & $375 / 376$ & $1446 / .1456$ & $0,478 *$ \\
\hline Rebanho bovino $>190$ animais $^{6}$ & $166 / 377$ & $384 / 1.464$ & 0,000 \\
\hline $\begin{array}{l}\text { Número de fêmeas }>24 \text { meses acima de } 120 \\
\text { animais } 6\end{array}$ & $107 / 371$ & $165 / 1.449$ & 0,000 \\
\hline Presença de outras espécies domésticas & $375 / 377$ & $1.451 / 1.464$ & $0,749 *$ \\
\hline Presença de ovinos/caprinos & $73 / 377$ & $186 / 1.464$ & 0,001 \\
\hline Presença de suínos & $215 / 377$ & $882 / 1464$ & 0,749 \\
\hline Presença de cães & $323 / 377$ & $1.272 / 1.464$ & 0,538 \\
\hline Presença de gato & $236 / 377$ & $969 / 1464$ & 0,191 \\
\hline Presença de animais silvestres & $152 / 377$ & $707 / 1464$ & 0,006 \\
\hline Aborto nos últimos 12 meses $^{7}$ & $113 / 363$ & $374 / 1.418$ & 0,126 \\
\hline Destino inapropriado do aborto $^{8}$ & $253 / 297$ & $1.028 / 1.149$ & 0,038 \\
\hline Não testa animais para brucelose & $276 / 375$ & $1.243 / 1.456$ & 0,111 \\
\hline Compra de reprodutores & $255 / 376$ & $909 / 1.458$ & 0,049 \\
\hline Vacina contra brucelose & $116 / 374$ & $164 / 1.459$ & 0,000 \\
\hline Abate reprodutor na fazenda & $103 / 371$ & $354 / 1.445$ & 0,196 \\
\hline Aluga pasto & $109 / 376$ & $362 / 1.454$ & 0,106 \\
\hline Gado com acesso a áreas alagadiças & $101 / 374$ & $379 / 1.459$ & 0,686 \\
\hline Ausência de piquetes de parto & $108 / 376$ & $630 / 1.456$ & 0,012 \\
\hline Ausência de assistência veterinária & $312 / 374$ & $1.283 / 1.453$ & 0,012 \\
\hline
\end{tabular}

*Teste exato de Fisher.

${ }^{1}$ leite + misto $\mathrm{x}$ corte (risco).

${ }^{2}$ corte + misto $x$ leite (risco).

${ }^{3}$ corte + leite $\mathrm{x}$ misto (risco).

${ }^{4}$ extensivo $x$ confinado + semiconfinado (risco).

${ }^{5}$ usa só IA x usa IA e touro + não usa IA (risco).

${ }^{6} 3^{\circ}$ quartil.

${ }^{7}$ não x sim + não sabe (risco).

${ }^{8}$ enterra, joga em fossa, queima x alimenta porco ou cão + não faz nada (risco). 
Tabela 6. Modelo final da regressão logística multivariada de fatores de risco (Odds ratio) para brucelose bovina em rebanhos com atividade reprodutiva no Estado do Tocantins, 2003

\begin{tabular}{lccc}
\hline Variável & Odds ratio & IC $(95 \%)$ & $p$ \\
\hline Número de fêmeas $>24$ meses acima de 120 animais & 2,00 & {$[1,51-2,63]$} & $<0,001$ \\
Vacina contra brucelose & 0,37 & {$[0,28-0,50]$} & $<0,001$ \\
Presença de piquete de parição & 0,72 & {$[0,55-0,94]$} & 0,015 \\
Exploração de leite & 0,63 & {$[0,45-0,88]$} & 0,007 \\
Abate de reprodutores na fazenda & 1,52 & {$[1,15-1,99]$} & 0,003 \\
\hline
\end{tabular}

IC: intervalo de confiança.

As prevalências de focos e de fêmeas foram elevadas para os dados consolidados para todo o Estado, porém há nítidas diferenças entre os circuitos. A região oeste do Estado, representada pelos circuitos $1,2,3$ e 5 , apresentou alta prevalência, e a região leste, representada pelos circuitos 4 e 6 , mostrou prevalência mais baixa (Tab. 2 e 3). Isso provavelmente decorre do sistema de produção predominante em cada uma dessas regiões, criando uma pecuária com dois perfis distintos: a pecuária da região oeste, onde existem propriedades com maior grau de tecnificação e que realizam trocas comerciais com maior frequência, com prevalência elevada, e a da região leste, onde se concentram as propriedades de subsistência, com prevalência mais baixa.

Apesar de os circuitos 4 e 6 apresentarem menor prevalência, ainda é possível reduzi-la por meio de vacinação de bezerras com a B19. Assim, todo o Estado poderá se beneficiar pela utilização da vacina B19 em bezerras, reduzindo a prevalência da brucelose a um custo muito baixo.

Os fatores de risco que emergiram da análise foram: rebanho com mais de 120 vacas e abate de reprodutores na propriedade (Tab. 6). Vacinar contra brucelose, ter piquete de parição ou rebanho a ser explorado para leite apresentaramse como fatores protetores (Tab. 6).

A vacinação de bezerras com a B19 como fator protetor indica que a porcentagem de focos de brucelose nas propriedades que vacinam é menor do que nas que não vacinam. É, portanto, um indicador de campo que comprova a eficiência da amostra B19.

O piquete de parição é uma medida simples de ser adotada, que visa reduzir o contato de animais não infectados com pastagens e aguadas contaminadas com material com alta concentração de brucelas (feto e seus anexos, restos placentários e líquidos vaginais oriundos de animais infectados). Em última análise, é um procedimento que diminui a dose de desafio e, portanto, protege contra a infecção.

O fato de a exploração para leite ter apresentado menor porcentagem de focos significa que a de corte ou a mista apresentaram porcentagem maiores de focos de brucelose. Isso decorre de as propriedades de corte ou mistas terem maior número de vacas que as de leite. De fato, as medianas de vacas das propriedades de corte, mistas e de leite foram, respectivamente, de 56, 48 e 39. A associação entre o tamanho de rebanho e a presença de brucelose foi demonstrada em vários estudos (Kellar et al., 1976; Nicoletti 1980; Salman e Meyer, 1984). Nos grandes rebanhos não há diferenças individuais quanto à suscetibilidade à doença, mas algumas características desses grandes rebanhos podem facilitar a transmissão da brucelose, tais como, maior frequência de reposição de animais, maior quantidade de problemas relacionados ao controle sanitário e influência na dinâmica da doença (Crawford et al., 1990). Christie (1969) observou que o aumento do rebanho resulta em aumento da probabilidade de ocorrer a doença e de persistir a infecção, e aumento da prevalência da doença e da dificuldade de erradicá-la. Assim, número elevado de animais no rebanho significa maior risco de introdução da brucelose pela compra mais frequente de reprodutores. E importante enfatizar que a introdução de animais significa risco real apenas quando praticada sem cuidados sanitários. Assim, ser propriedade de corte ou mista no Estado significa ter mais animais e introduzir reprodutores com maior frequência. Esse resultado, portanto, sugere, de forma indireta, que a introdução de reprodutores é a prática que está associada à condição de foco da brucelose. Esse raciocínio é corroborado pelo 
fato de "ter mais do que 120 vacas" ter-se apresentado como fator de risco.

O abate de reprodutores na propriedade foi considerado por Sanchez et al. (1998) uma atividade de risco e tem significado importante na transmissão da brucelose, visto que tanto a carcaça quanto as vísceras e a formação de aerossóis podem contaminar o homem e o ambiente próximo ao local do abate.

Recomenda-se: concentrar esforços na obtenção, em todos os anos, de uma cobertura vacinal mínima de $80 \%$ de fêmeas entre três e oito meses de idade com a vacina B19; incentivar a adoção de piquetes de parição e desencorajar a introdução de reprodutores sem cuidados sanitários e o seu abate nas propriedades.

\section{AGRADECIMENTOS}

À FAPESP, ao CNPq e ao MAPA pelo apoio financeiro. Agradecimento à ADAPEC pelo apoio logístico.

\section{REFERÊNCIAS BIBLIOGRÁFICAS}

BRASIL. Ministério de Agricultura, Pecuária e Abastecimento. Programa Nacional de Controle e Erradicação da Brucelose e da Tuberculose Animal (PNCEBT): Manual técnico. Brasília, 2006. 184p.

CHRISTIE, T.E. Eradication of brucellosis in northern Ireland: Field problems and experiences. Vet. Rec., v.85, p.268-269, 1969.

CRAWFORD, R.P.; HUBER, J.D.; ADAMS, B.S. Epidemiology and surveillance. In: NIELSEN, K.; DUNCAN, J.R. (Ed.). Animal brucellosis. Boca Raton: CRC Press, 1990. p.131-151.

DEAN, A.G.; DEAN, J.A.; COLOMBIER, D. et al. Epi-Info, version 6: A word processing database and statistics program for epidemiology on microcomputers. Atlanta: CDC, 1994. 601p.

DOHOO, I.; MARTIN, W.; STRYHN, H. Veterinary epidemiologic research. Charlottetown, Canadá: Atlantic Veterinary College, 2003. 706p.
FLETCHER, R.H.; FLETCHER, S.W.; WAGNER, E.H. Clinical epidemiology: The essentials. 2.ed. Baltimore: Williams \& Wilkins, 1998. 246p.

IBGE. Rio de Janeiro, 2005. Disponível em: $<$ http:www.sidra.ibge.gov.br $>$. Acessado em: 7 mai. 2007.

KELLAR, J.; MARRA, R.; MARTIN, W. Brucellosis in Ontario: A case control study. Can. J. Comp. Med., v.40, p.119-128, 1976.

NICOLETTI, P. The epidemiology of bovine brucellosis. Adv. Vet. Sci. Comp. Med., v.24, p.69-98, 1980.

PAULIN, L.M.; FERREIRA NETO. J.S. A experiência brasileira no combate à brucelose bovina. Arq. Inst. Biol. São Paulo, v.69, p.105$112,2002$.

SALMAN, M.D.; MEYER, M.E. Epidemiology of bovine brucellosis in the Mexicali Valley, México: Literature review of disease-associated factors. Am. J. Vet. Res., v.45, p.1557-1560, 1984.

SANCHEZ, A.L.; CEPEDA, A.R.; MORANO, T.S. Analisis de un brote epidemico de brucellosis en trabajadores en mataderos. Rev. Esp. Salud Publ., v.72, p.137-146, 1998.

SILVA, A.R.P.; ALMEIDA, M.G. O agronegócio e o Estado do Tocantins: O atual estágio da consolidação. Caminhos de Geografia, v.8, p.28-45, 2007. Disponível em $<$ http://portal.mec.gov.br/setec/arquivos/pdf/agro pec_to.pdf $>$ Acessado em: 10 set. 2007.

THRUSFIELD, M. Veterinary epidemiology. 3.ed. Oxford: Blackwell Science, 2007. 610p.

TOCANTINS. Agência de Defesa Agropecuária. A agropecuária do Estado de Tocantins. [200-]a. Disponível em $<$ http://portal.mec.gov.br/setec/arquivos/pdf/agro pec_to.pdf $>$ Acessado em: 10 set. 2007.

TOCANTINS. Secretaria da Indústria e do Comércio. Potencial econômico. [200-]b Disponível em $<$ http://www.logos.to/exec/index.php?acao=toca ntins\&secao=3> Acessado em: 23 out. 2007. 